\title{
Cincuenta números de Letras $^{1}$
}

\section{Sherry E. Gapper ${ }^{2}$}

\author{
Universidad Nacional, Costa Rica
}

\begin{abstract}
resumen
Se ofrece una crónica del desarrollo de Letras, desde su fundación, en 1979, hasta la actualidad. Es un análisis comentado de las políticas editoriales, sus orientaciones académicas generales a lo largo de los años, las áreas disciplinarias y demás asuntos atinentes a una publicación periódica de esta índole. Se señala la diversidad de aspectos y factores que han permitido una lenta evolución, desde un primer perfil entre revista literaria y universitaria, hasta su consolidación como revista académica dedicada a los estudios lingüísticos, literarios, sobre adquisición y enseñanza de lenguas, lenguas indígenas y nuevas corrientes en las ciencias del lenguaje.
\end{abstract}

\begin{abstract}
The development of Letras is chronicled from its founding in 1979 up to the present. An analysis is provided of editorial policies, its general academic orientation as it evolved, the disciplines covered, and other issues characteristic of this type of periodical. Mention is made of a number of aspects and factors which have contributed to its gradual shift from its first profile as a university, literary publication to its consolidation as an academic journal devoted to linguistics, literary studies, language teaching and acquisition, and indigenous languages, along with new currents in language sciences.
\end{abstract}

Palabras clave: publicaciones periódicas, revistas literarias, estudios linguiísticos, teoría y crítica literarias

Keywords: periodicals, literary journals, linguistics, literary criticism and theory

1 Recibido: 3 de febrero de 2011; aceptado: 7 de julio de 2011.

2 Escuela de Literatura y Ciencias del Lenguaje. Correo electrónico: sherry.gapper.morrow@una.cr

$$
L_{\text {etras }} 50 \text { (2011), ISSN 1409-424X }
$$




\section{Preámbulo}

El hecho de que una revista académica, como Letras, haya persistido a lo largo de más de tres decenios, resulta llamativo, sobre todo si se tiene en cuenta que prácticamente ha recorrido la historia misma de la Universidad Nacional. Muchas revistas análogas, en nuestra época, han tendido a la especialización, puede que excesiva en nuestro medio, en detrimento de productiva interacción académica entre los diversos campos afines ${ }^{3}$. Letras ha procurado conservar ese principio de variedad disciplinaria, abarcándola en ese nombre original de la revista, quizá muy genérico pero eficaz para sus propósitos fundacionales. Además, esa amplia base temática consolidada de Letras propicia la inclusión de nuevas áreas y fomenta su exploraciónsistemática.

Para la Escuela de Literatura y Ciencias del Lenguaje ha sido esencial contar con un espacio reconocido para la difusión de los resultados de sus análisis e investigaciones, en un momento de transición en muchos aspectos de los estudios lingüísticos, literarios y culturales.

Al publicarse ya medio centenar de números, conviene reflexionar sobre los alcances de la revista, como la oportunidad para identificar áreas importantes no solo de la revista sino de la institución que representa; porque evaluar una parte del trabajo académico es analizar en forma integral lo que se ha llevado a cabo durante estos treinta y cinco años de historia. Como una de las primeras publicaciones de la Facultad de Filosofía y Letras (Universidad Nacional, UNA), desde su creación Letras ha ejercido influencia en sus unidades académicas por su voluntad editorial interdisciplinaria, tanto entre las diversos campos de especialización de la Escuela de Literatura y Ciencias del Lenguaje (ELCL), como entre los de esta escuela y demás espacios la Facultad. Su pertinencia es palpable y

3 También, de manera parcial, da cuenta de este proceso de desarrollo y consolidación la ponencia sobre la revista Letras, «Letras: una aspiración al diálogo y la integración académica», de Sherry E. Gapper, presentada el 22 de octubre 2008, durante el Encuentro internacional del universo de las revistas culturales y académicas en América Latina, auspiciado por la Facultad de Filosofía y Letras. 
demostrada en los artículos publicados en los diversos números y en la variedad de campos de especialización de sus autores.

\section{El desarrollo de la revista desde distintos puntos de vista ${ }^{4}$}

Para esta retrospectiva, se examinaron todos los cincuenta números de la colección así como información que corresponde a hechos significativos y modificaciones fundamentales que reflejan no solo la evolución de la revista sino la de las instituciones en ella representadas. Se presenta una crónica del desarrollo de la revista lo cual no se había realizado hasta ahora en el caso de Letras. La evolución de una revista se da en el tiempo pero también en diversos espacios temáticos y se aborda simultáneamente desde ambas perspectivas.

La revista Letras apareció en 1979. Su concepción inicial combinaba aspectos de una revista artística y literaria con los de una publicación académica. Además de estudios y artículos, publicaba poesía, y en sus primeros números se le dio atención a lo gráfico. También se creó una interesante sección de «documentos» (que todavía se conserva), que contiene material significativo para la historia literaria (por ejemplo, la polémica sobre el nacionalismo en los inicios de la literatura costarricense), así como artículos especializados sobre estudios literarios o lingüísticos y, un poco después, sobre la enseñanza de lenguas y traducción. Esta última orientación es la que prevaleció y Letras se empezó a consolidar como revista propiamente académica. Su trayectoria da cuenta de los sucesivos campos de interés en la investigación y la docencia de la ELCL y en otras instituciones de enseñanza superior. A la vez, se pueden rastrear en sus sucesivos números las huellas del estado y del desarrollo de las corrientes teóricas y metodológicas así como de los temas y de las disciplinas en el plano internacional.

4 Para seguir de cerca la evolución de la revista, se puede consultar en las bibliotecas de la UNA, o bien se dispone de la colección de Letras en formato digital en el portal de las revistas de la Universidad Nacional en: <www.revistas.una.ac.cr/letras〉. 
Aparte del profesorado de la ELCL o de la UNA, han publicado especialistas de universidades e instituciones nacionales y de varios países de Europa, Asia, África, América Latina y Norteamérica. Algunos de los cincuenta números publicados hasta el momento se han dedicado a actas de los congresos de especialistas o a un tema en especial.

Un repaso de los índices de Letras permite describir el desarrollo mismo de las disciplinas de la Escuela de Literatura y Ciencias del Lenguaje y de la propia Facultad de Filosofía y Letras, y también ha sido un fiel reflejo de la evolución de los temas de interés de los planes de estudio. Una unidad académica como la ELCL, en la que convergen variadas disciplinas requiere aprovechar espacios como el que ha propiciado a lo largo de los años esta revista, para buscar puntos de confluencia entre las diversas especialidades. Un análisis de las revistas publicadas hasta la actualidad, ilustra el desarrollo de estas áreas disciplinarias.

El cuadro 1 presenta un panorama general de los principales campos temáticos de la revista y que se retomarán más adelante.

\section{Cuadro 1. Principales campos temáticos de Letras}

\begin{tabular}{|c|}
\hline - $\quad$ Artes gráficas (solo en los primeros números) \\
\hline - Creación literaria (solo en los primeros números) \\
\hline $\begin{array}{ll}\text { - } & \text { Lingüística (y estudios del lenguaje) } \\
\text { - } & \text { Lingüística (y lenguas indígenas) } \\
\text { - } & \text { Lingǘííica aplica aplicada a la enseñanza a la enseñanza del español }\end{array}$ \\
\hline $\begin{array}{l}\text { - Literatura } \\
\text { - Literatura costarricense } \\
\text { - Literatura en lengua francesa } \\
\text { - Literatura en lengua inglesa } \\
\text { - Literatura española } \\
\text { - Literatura hispanoamericana } \\
\end{array}$ \\
\hline - Semiótica \\
\hline - Teoría literaria y estética \\
\hline - Traducción e interpretación \\
\hline
\end{tabular}




\section{Letras 1 (1979)}

Varios de los autores, e incluso impulsores de este primer número, ya hace más de tres decenios, aún participan en los quehaceres de esta institución ${ }^{5}$. Los primeros tópicos —el uso de la lengua materna, estudios sobre poesía latinoamericana y extranjera - son líneas temáticas que se han retomado una y otra vez. En ese primer número, Isaac Felipe Azofeifa publica su ensayo «Imagen universal del hombre latinoamericano» (153-164) la universalidad de quienes habitan Latinoamérica; Azofeifa afirma que «el amo europeo y el norteamericano ya no son amos de nuestro espíritu, de nuestro destino, porque ellos tampoco lo son del suyo. Todos estamos en busca de nuestro destino. Es hora del encuentro con nuestro destino universal» (163).

Aparte del ensayo de Azofeifa, el primer número contiene dos artículos sobre el uso de la lengua, escritos por conocidos lingüistas, «Problemas aspectuales del uso de hasta», de Ronald Ross (3-19), y «Consideraciones acerca de la noción de 'perífrasis verbal' en español», de Gastón Gaínza (21-54); así como tres estudios literarios «La indómita palabra», de Carlos Francisco Monge y Guillermo Barzuna (55-95), «Algunas posibilidades del conocimiento sobre la literatura», de Carlos Aguirre Gómez (97-107) y «La poesía óptica de E. E. Cummings», de José Otilio Umaña (109-112). Además, en la sección «Obras literarias, pictóricas y biográficas», se publicaron «Seis dibujos», de Néstor Zeledón Guzmán (113-119), «La tercera alegría», poemas de Jorge Charpentier (121-130), «Un punto de partida», de Mayra Jiménez (131-136), «lleana», de Eduardo Saxe Fernández (137-152), y «Autobiografía campesina (fragmento)», de Luis Felipe Hernández Hernández (165-172). Como «documento», se eligió

5 Según consta en la contraportada del primer número de la revista, participaron como directores Antidio Cabal G., Zoraida Ugarte N., Carlos Aguirre G. y David Pinto D.; como miembros del comité de redacción Oscar Chavarría A., Juan Durán L., Ronald Ross V. y Carlos Salazar R.; y como colaboradores Gastón Gaínza A., Mayra Jiménez R., Sherry Gapper M. (como traductora) y Eduardo Saxe F.

6 En adelante los números de página del número respectivo se consignarán entre paréntesis. 
un extracto de «Las categorías literarias», de Roberto Brenes Mesén (173-218), que su autor cierra con esta afirmación: «...[las letras] pueden sobrevivir y llevar fruto sólo en la más absoluta libertad, sin otro gobierno que el de las leyes recónditas que sigue el alma humana en su obra de creación» (218), frase que aún hoy, tantos años después, es una advertencia válida en momentos en que existen amenazas y restricciones en la forma en que debemos expresarnos.

\section{Los años que siguen}

El primer número de una revista tiende a fijar sus características y sus derroteros. Tal ha sido el caso de Letras. Siguiendo el patrón de su primer número, en Letras 2 aparece un artículo sobre el lenguaje, tres sobre literatura, un documento en la sección «Obras literarias, pictóricas y biográficas» dos relatos, dos conjuntos de poemas y una obra pictórica. Uno de los artículos, el de Carlos Rafael Duverrán, «Notas para una reseña de la literatura costarricense» (187-220), ha contribuido a definir las letras costarricenses, a partir de una mirada prospectiva:

Es evidente que el aporte de estos movimientos enraíza con los mayores elementos de lo tradicional, y que sobre sus bases se desarrolla, con cierta continuidad, la evolución de esos géneros literarios, que en el momento actual presentan gran riqueza y diversidad por la conjunción de escritores de distintas generaciones y tendencias. El panorama presente, más que al ahora, pertenece al futuro, cuando los ciclos que aún no se cierran puedan mirarse con la debida perspectiva (219).

Desde ese futuro que ya se vive, se observa que en los años siguientes, además de los estudios literarios, se publica una serie de artículos referidos a temas lingüísticos, campo de creciente importancia en la institución. Eran los años en que estaba activo en la ELCL un programa de doctorado en linguiística, con la participación 
y apoyo de destacados expertos, nacionales y extranjeros. Con el tiempo se abarcarían temas de lenguas indígenas costarricenses y del bilingüismo de Limón, asuntos aún vigentes en la actualidad. Ya en otros números se considera también el español de Costa Rica. Siguen también los estudios sobre la literatura, con predominio de obras literarias escritas en español.

En el número doble 6-7, se publicó «Limón: educación y bilingüismo», de José Bogarín y Ronald Ross (205-257), el primero de varios sobre esa temática. Además, dada su importancia, Letras se encargó de la traducción al español de parte de un estudio realizado por Anita Herzfeld, profesora visitante en Costa Rica en ese entonces, el cual quedó publicado en Letras 10: «Un ejemplo de la progresión lectal en el contínuum criollo: do en el criollo limonense» (121137). Seguiría otro artículo de la misma autor en el número 25-26 de Letras, «La autoimagen de los hablantes del criollo limonense» (139-158), en que se cuestiona la aculturación a la que se sometía la zona atlántica:

El cambio que han sufrido las regiones de la zona atlántica, desde el tiempo en que el inglés fuera favorecido por la Compañía hasta que se dio la centralización de las autoridades del Estado, trajo como consecuencia una intensa aculturación de las minorías a la expansión funcional de las normas nacionales, incluyendo al español, el idioma oficial (156).

Herzfeld destaca asimismo que esto había sido en parte el resultado de una orden del Ministerio de Educación, que intentó «suprimir toda educación en inglés [en la zona atlántica] y nacionalizar la región» (155). Letras no se quedó al margen de fundamentales temas sociales y lingüísticos que influyen en el desarrollo de la calidad de la educación en el país. Mirada ya desde el futuro de aquel momento, esta situación muestra lo perjudicial que sería que la academia sirviera solo para cumplir con directrices políticas. También 
muestra lo esencial que es la autonomía universitaria y la necesaria independencia de una revista académica, como agentes de cambio y de generación de conocimientos.

Por otra parte, pese a la importancia que se les prestaba en las diversas instituciones costarricenses, tardaron un poco más en llegar a Letras los primeros artículos sobre las lenguas indígenas, tema que ha cobrado creciente importancia. La lingüista Margaret Dickemann fue la primera en publicar en Letras, en el número doble 8-9, un estudio sobre una lengua indígena: «El conflicto entre la sintaxis y el discurso en jacalteco» (259-287). Se trata de una lengua maya que se habla en el norte de Guatemala. Más adelante en Letras 15-16-17, Juan Santiago Quirós publica el primer estudio sobre una lengua indígena de Costa Rica, «Términos chorotegas en la toponimia guanacasteca» (161-170); y María Eugenia Villalobos Gamboa, en Letras 29-30, «Bribri: lengua con cláusulas relativas del núcleo interno» (225-239). El guatuso también está presente en Letras 37 en «Etnoornitología guatusa»(139-165), de Ginneth Pizarro Chacón. Avanzando aun más se hace presente en Letras 39 una actitud renovadora hacia las lenguas indígenas en Costa Rica, en «Actitudes hacia la enseñanza de las lenguas indígenas» (267-273), de Carmen Rojas Chaves. Seguirán otros artículos más sobre el boruca, el buglere, el guaymí y otros en Letras 43, número temático en el que se publicaron ponencias seleccionadas del I Simposio de Programa Lenguas Indígenas de la Baja Centroamérica.

El español de Costa Rica ha sido un tema fundamental y ha sido abordado desde muy diferentes perspectivas. Desde «El vocabulario del trapiche costarricense», de Jorge Alberto Alfaro Pérez, en Letras 8-9 (217-257), hasta la de la lingüística histórica de Miguel Ángel Quesada, «Aspectos del español en Costa Rica en documentos de la época colonial», Letras 15-16-17 (61-70), Veinte años después, Quesada publicaría Historia de la lengua española en Costa Rica ${ }^{7}$ y

7 Miguel Ángel Quesada, Historia de la lengua española en Costa Rica (San José, EUCR, 2009). 
otros valiosos estudios sobre el tema; también publicó en Letras 37 su análisis «El participio con complemento pronominal en el español de Costa Rica» (5-29). Otros autores más se han referido a temas afines y quizás estos artículos constituyen una base para intensificar en la ELCL el interés que se desarrollara más adelante en la enseñanza de la lengua materna.

\section{A partir del los primeros diez números}

En el número doble 11-12, de Letras (de 1983), además de varios estudios literarios, se publica por primera vez un artículo sobre la enseñanza de una segunda lengua, «Teoría y práctica de la respuesta física total» (7-29), de Wolf Hollerbach, Lelia Villalobos, Elsa Atencio y Sherry Gapper. Al mismo tiempo, en la Escuela de Literatura y Ciencias del Lenguaje empezó a cobrar más importancia el campo de la enseñanza de lenguas, como lo manifestó la fundación de la Licenciatura en la Lingüística Aplicada a la enseñanza del Inglés como lengua extranjera.

En el siguiente número, se publica un artículo sobre la enseñanza de la lengua materna, producto también de esta nueva orientación, «La enseñanza del español en crisis», Letras 13-14 (7-19), de Flora Ovares (quien más adelante fungiría de directora de Letras durante unos años ${ }^{8}$ ), junto con Jorge Alfaro, Margarita Rojas y Sonia M. Mora; ellos presentan los resultados de un estudio más amplio del que da cuenta la pequeña obra La palabra al margen, en la que intentan «no solo describir la situación problemática sino...explicar sus componentes, su dinámica, su génesis» (10). Siguen otros más; entre ellos: «Nuevos contenidos para la enseñanza del español en III ciclo y educación diversificada», Letras 15-16-17 (145-159), de Rolando Zamora; y «El manejo del texto y su relación con la comprensión lectora», Letras 18-19 (5-26), de María del Carmen Ugalde.

8 En orden cronológico, luego del grupo fundador ya señalado, quienes han fungido como directores son: Faustino Chamorro (a partir de Letras 11-12), Carlos Francisco Monge (a partir de Letras 23-24), Juan Durán Luzio (Letras 31), Flora Ovares (Letras 32-37) y Sherry E. Gapper (a partir de Letras 38). 
Unos años más tarde el área temática de lingüística aplicada iniciada en Letras 11-12 da nuevos frutos a partir del número 23-24, en el que Jorge Hernández Villalobos publica «The Socio-Cultural Content of Textbooks and the Teaching of Culture in Foreign Language Programs» (83-104), referido a la enseñanza del inglés; y en el siguiente número 25-26, Virginia Vega Carballo ofrece el primer artículo sobre la enseñanza del francés, «Fonética y enseñanza del francés» (209-219). Seguirán otros cincuenta títulos más en que se presentan estudios realizados sobre diversos aspectos de la enseñanza, el aprendizaje y la adquisición de un idioma extranjero, tanto para el caso del francés como del inglés como lenguas extranjeras. Entre ellos se eligió también para la sección de «Documentos» un ensayo de José de Caso «La enseñanza del idioma» en Letras 44 (255-262), viejo estudio en el que ya se ponían en entredicho muchos de los mismos asuntos que se debaten hoy día. En un momento en que el mundo editorial tiende a fomentar la aparente renovación por razones comerciales, la sección de «Documentos» permite a la comunidad académica conocer los estudios de épocas anteriores.

\section{Memorias de congresos}

La revista, como publicación, no ha adoptado como programa influir o promover modificaciones o reorientaciones académicas en la institución; antes bien, su trayectoria refleja el resultado de los cambios y la evolución en las diversas especialidades albergadas en sus páginas. Desde luego, ha habido ocasiones para fomentar cambios, como son los congresos académicos de cuyos estudios la revista se ha alimentado. Bajo la dirección del profesor Faustino Chamorro, se recogió en Letras 15-16-17 (1986) una selección de casi cuarenta ponencias presentadas en el Segundo Congreso Nacional de Filología, Lingüística y Literatura, llevado a cabo ese año en la Universidad Nacional, con participantes nacionales y extranjeros. Ese congreso marcó el inicio de una etapa de proyección de la institución, así como la introducción de nuevos temas. 
Siguieron otros congresos, como el III Congreso de Sociocrítica, llevado a cabo en Costa Rica en 1993, del que se recogen en Letras 33 algunas de las ponencias presentadas. En otro número se reproducen ponencias del XCongresode Filología, Lingüísticay Literatura celebrado en 2003. A eso se suman varios simposios sobre lenguas indígenas, y las tres ediciones del Congreso Internacional de Lingüística Aplicada (CILAP, 2007, 2009, 2011), en que se tratan la enseñanza de la literatura y las lenguas extranjeras y la materna, la traducción, entre otros asuntos. De las ponencias presentadas, algunos de sus autores han elaborado artículos que llegaron a formar parte de Letras. Más recientemente el $x x$ Congreso Internacional de Literatura Centroamericana (CILCA, 2012) ha llegado a nutrir la revista con artículos basados en algunos de los estudios presentados (Letras 49-50). El desarrollo de la Escuela de Literatura y Ciencias del Lenguaje y su ampliación temática ha enriquecido la revista al igual que lo han hecho los diversos congresos auspiciados por la Escuela, los cuales han permitido también la interacción con profesionales de otras universidades nacionales e internacionales.

\section{Los estudios literarios}

El CILCA versó sobre la literatura centroamericana contemporánea. Este campo ha sido, cuantitativamente, el predominante en la trayectoria de Letras. Casi la mitad de los artículos publicados se refieren al análisis de obras literarias: noventa estudios sobre obras literarias costarricenses, once sobre obras literarias en lengua francesa; doce sobre obras literarias en lengua inglesa; dieciocho sobre obras literarias españolas; un centenar sobre obras literarias hispanoamericanas y diez sobre literatura en otras lenguas. Los análisis se han orientado desde muy variadas aproximaciones y dan muestra de la evolución y de las posibilidades adoptadas por autores particulares sobre los temas y objetos de estudio. Se han introducido nuevos métodos de análisis y se han dado a conocer obras poco investigadas. 
Sobre teoría literaria y estética hay también unos ocho estudios y sobre aspectos semióticos otros doce.

El primer estudio sobre literatura escrita en inglés, ya señalado, apareció en el primer número y siguieron otros artículos más, pero hubo que esperar hasta Letras 11-12 para contar con uno referido a una obra literaria en francés: «Sobre tres poemas de Victor Hugo» (71-101), de Juan Durán Luzio. En ambos casos el interés fue aumentando con el tiempo, con el fortalecimiento de los programas de lenguas extranjeras y el creciente interés en el ámbito internacional en general. Sin embargo, se han publicado relativamente pocos estudios sobre literatura escrita originalmente en otras lenguas, no como política editorial de la revista, sino resultado de las posibles contribuciones que le llegaban: algunos referidos a literatura en árabe, en alemán, en griego, y siempre por medio de su versión en español o en francés.

Esta especie de vocación natural de la revista por abrir sus páginas a las letras (en rigor, a las manifestaciones literarias) ha sido una constante. Desde luego, los estudios sobre las letras costarricenses ocupan un lugar destacado, no solo porque atienden lo más cercano, sino porque se responde a unas directrices académicas de estudiar el patrimonio literario costarricense, el del pasado y el contemporáneo. Figuran varios estudios sobre autores del canon nacional (Manuel González Zeledón, Joaquín García Monge, Roberto Brenes Mesén, Carlos Gagini), pero también los hay sobre nuevas alternativas a las letras nacionales, con estudios sobre Max Jiménez, Isaac Felipe Azofeifa, Eunice Odio o Fernando Contreras. Mención aparte merece la recuperación de algunos viejos documentos sobre la literatura nacional, que se han reunido, en sucesivos números de la revista en la sección «Documentos», como ha quedado dicho. Vale la pena mencionarlos, título a título: «Las categorías literarias», de Roberto Brenes Mesén (Letras 1); la «Polémica entre nacionalismo y literatura», en la que intervinieron varios escritores ilustres en la etapa de formación de las letras costarricenses (Letras 8-9); «La posición de 
los actuales estudios literarios y lingüísticos y nuestra enseñanza del castellano», de Isaac Felipe Azofeifa (Letras, 29-30); «Cronología de la Academia Costarricense de la Lengua» (Letras 40), de Arturo Agüero; «Carta literaria», de Justo A. Facio (Letras 41); «Literatura patria», de José Fabio Garnier (Letras 45 y 46), y una «Breve antología de poemas en prosa costarricenses» (Letras 47).

Los otros dos universos mayores de la literatura escrita en español, el peninsular y el hispanoamericano, también han recibido a lo largo de estos tres decenios, particular atención, no solo por el valor intrínseco de obras y autores, sino también por su influencia en las letras costarricenses. Así, Letras ha publicado interesantes estudios sobre clásicos del siglo áureo (el Lazarillo, Lope de Vega, Cervantes), o sobre la poesía española contemporánea (de escritores de las generaciones del 27 y del 36), y uno sobre las relaciones entre la poesía costarricense y la española: «Andanzas españolas de la poesía costarricense» (Letras 47), de Carlos Francisco Monge. De su abundancia y variedad, no faltan meticulosos análisis de las mejores plumas hispanoamericanas: Darío, Rodó, Asturias, Neruda, Carpentier, Paz, Roa Bastos, Borges, Cortázar, Fuentes, Cardenal. También hay estudios sobre clásicos como las «Cartas de navegación» de Colón, el Periquillo Sarniento o el Martín Fierro.

\section{Contactos entre culturas y lenguas}

Otro conjunto de estudios son los que se ocupan de traducción literaria, campo que se había desarrollado relativamente poco en Costa Rica. El estudio «La historia de la traducción como tarea de investigación de las letras nacionales» (125-142), de Miguel Ángel Vega Cernuda, da cuenta de esa situación y señala algunas vetas de interés. Se destacan en particular los recientes análisis de traducciones de literatura costarricense al alemán, al francés y al italiano, también recogidos en Letras 43: «Recepción y traducción en alemán de Mamita Yunai de Carlos Luis Fallas», de Vega Cernuda (143156); «La traducción alemana de Marcos Ramírez de Carlos Luis 
Fallas», de Pino Valero (157-176); «La traducción del espacio novelesco de Fernando Contreras Castro y su transferencia a la realidad alemana», de Juan Antonio Albaladejo (177-192), y «La recepción del Mamita Yunai de Carlos Luis Fallas en Italia y Francia: entre la proximidad lingüística y la divergencia cultural», de Javier García Albero (193-205). A estos se suma «Mamita Yunai: una traducción al húngaro», de Judit Tomcsányi (69-86) en Letras 46, donde se afirma lo siguiente:

Todas las culturas del mundo tienen en común, por la misma naturaleza humana, ver a otras culturas como «el otro», en el sentido de «lo diferente», «lo extraño», «lo ajeno», a lo cual las relaciones de poder añaden las connotaciones, o bien de «respetable», «envidiable», «apreciable», o por el contrario, «temible» o «despreciable» (71).

Evidentemente, la traducción como ejercicio y una revista académica dedicada a las letras tienen que encontrar puntos de encuentro. Se hacen confluir lenguas, culturas y perspectivas que permiten tomar distancia y comprender, con más detenimiento, esa tan buscada y al mismo tiempo elusiva otredad. Los estudios sobre traducción habían comenzado a cobrar más importancia en Letras a partir del número 15-16-17, con el artículo de Óscar Chavarría: «Reflexiones sobre la traducción», (21-35). Seguiría otro en Letras 23-24, junto con diversos estudios del campo de la lingüística aplicada. Publicado en 1990, ese número da cuenta de las nuevas inquietudes de nuestro claustro y de nuestra sociedad. Algunos años después se fundaría el Plan de Licenciatura en Traducción como respuesta a las nuevas necesidades de mediación cultural y lingüística en el ámbito costarricense. En 2004, se publicó un número dedicado principalmente a la traducción e interpretación y a la enseñanza de lenguas y literaturas. No es casual que en años anteriores se habían fundado en la Escuela de Literatura unos programas de posgrado en sendas especialidades. 
En los números posteriores observamos, en muy diversos campos - literatura, traducción, lingüística, enseñanza de idiomas extranjeros, lenguas indígenas, teoría literaria- el desarrollo continuo y constante de lo que ya había años antes. Se retoman en cada especialidad temas fundamentales una y otra vez desde muy distintas perspectivas. Empiezan las referencias a nuevas teorías y conceptos de la semiótica, del análisis de aspectos culturales y la enseñanza de nuevos conceptos. Aparecen renovados acercamientos a los diversos campos de estudio y a una nueva disposición para la generación de conocimientos.

\section{Quiénes escriben: algunas obligadas estadísticas}

Según lo visto, Letras no se ha quedado al margen de los temas que tendrían más adelante importantes repercusiones. Se han mencionado los estudios sobre lenguas indígenas, la enseñanza de lenguas extranjeras y maternas, los factores políticos que influyeron en la situación lingüística de la zona atlántica y la literatura como un representación de referentes sociales y culturales. Por ello cabe analizar el perfil de quienes han publicado en Letras desde su inicio: primordialmente docentes universitarios e investigadores de las diversas áreas disciplinarias de las humanidades.

En los diez primeros números - es decir, durante los primeros cuatro años- quienes publicaron sus artículos suman ciento nueve personas, de las cuales veinticuatro son mujeres (menos del 25\%), proporción que ha variado significativamente con el tiempo, hasta hoy día. Como reflejo de lo que ocurre en su entorno, y sin que la administración de la revista se lo hubiera propuesto, ocurrió un cambio en la proporcionalidad de contribuyentes, según fueran mujeres o varones. En los números sucesivos (entre el 11 y el 21, por ejemplo) ya se manifiestan notables diferencias: de noventa y cinco contribuyentes, cincuenta y dos son varones y cuarenta y tres mujeres. El número doble 11-12 es el primero en que la cantidad de mujeres iguala 
la de los varones, y ya en el 18-19 se da una proporción inversa. La tendencia se mantuvo y en los siguientes conjuntos de números (2230) y (31-40) la cantidad de autoras supera la de hombres, como se observa en el cuadro 2. En total de casi quinientas personas que han publicado en Letras, durante estos casi treinta y cinco años, doscientos setenta y tres son varones y doscientos dieciocho mujeres. Sin embargo, es esencial indicar que en ningún momento ha sido política de Letras excluir o incluir un artículo por razones de género; las diferencias han sido resultado de cambios externos a la revista.

Cuadro 2. Contribuyentes de artículos (según sexo)

\begin{tabular}{|c|c|c|r|}
\hline Números de Letras & Varones & Mujeres & Total \\
\hline 1 a 10 & 85 & 24 & 109 \\
\hline 11 a 21 & 52 & 43 & 95 \\
\hline 22 a 30 & 23 & 29 & 52 \\
\hline 31 a 40 & 53 & 71 & 124 \\
\hline 41 a 50 & 60 & 51 & 111 \\
\hline & $\mathbf{2 7 3}$ & $\mathbf{2 1 8}$ & $\mathbf{4 9 1}$ \\
\hline
\end{tabular}

Otra perspectiva desde la que debe conocerse a fondo una revista, sobre todo académica, es la que tienen que ver con las políticas adoptadas con relación a los idiomas. Desde el primer número se publican estudios, escritos en español, sobre obras literarias en inglés. Aparte de estudios como ese, en esos primeros años era política editorial traducir artículos, cuando ello se estimaba oportuno. Tal es el caso de estudios como el de Letras 3, «Épica y soledad en El otoño del patriarca» (3-45), o como el de Letras 10, «Hacia la búsqueda de la identidad peruana» (159-189), originalmente en inglés. En ese momento no se consideraba aún la posibilidad de publicar en otras lenguas, reflejo de una política lingüística entonces prevalente.

No fue sino hasta la aparición de Letras 13-14 cuando se publicó un artículo en inglés: «A Further Look at the Dramatic Parallels 
in García Lorca and Tennessee Williams: The Poetic Qualities and Symbolism in Yerma and The Purification» (89-102), de Taño-Manning y Manning. Esta apertura se dio de manera relativamente lenta; el siguiente artículo fue escrito en francés: «Remuer des tonnes d'annés: Yadira Calvo re-lit la littérature» (217-227), de Letras 1819. En la medida en que se abría paulatinamente la academia costarricense a los contactos efectivos con universidades del exterior fueron admitidos cada vez más artículos escritos en otras lenguas. A partir de Letras 23-24, en que figuran dos artículos en inglés, se ha aceptado en cada número un promedio de dos artículos, en inglés o en francés, como se indica en una muestra parcial en el cuadro 3.

\section{Cuadro 3. Artículos publicados en inglés o en francés}

\begin{tabular}{|l|c|c|c|c|c|c|c|c|c|c|}
\hline número & $\mathbf{2 5 - 2 6}$ & $\mathbf{2 7 - 2 8}$ & $\mathbf{2 9 - 3 0}$ & $\mathbf{3 1}$ & $\mathbf{3 2}$ & $\mathbf{3 3}$ & $\mathbf{3 4}$ & $\mathbf{3 5}$ & $\mathbf{3 6}$ & $\mathbf{3 7}$ \\
\hline Inglés & 1 & 2 & 2 & 2 & 1 & 1 & 2 & 0 & 3 & 0 \\
\hline Frances & 0 & 0 & 1 & 1 & 1 & 0 & 1 & 0 & 0 & 1 \\
\hline
\end{tabular}

\begin{tabular}{|l|c|c|c|c|c|c|c|c|c|c|c|}
\hline número & $\mathbf{3 8}$ & $\mathbf{3 9}$ & $\mathbf{4 0}$ & $\mathbf{4 1}$ & $\mathbf{4 2}$ & $\mathbf{4 3}$ & $\mathbf{4 4}$ & $\mathbf{4 5}$ & $\mathbf{4 6}$ & $\mathbf{4 7}$ & $\mathbf{4 8}$ \\
\hline Inglés & 0 & 1 & 2 & 3 & 0 & 0 & 6 & 0 & 3 & 2 & 3 \\
\hline Frances & 1 & 0 & 0 & 1 & 7 & 0 & 0 & 0 & 0 & 0 & 0 \\
\hline
\end{tabular}

Diversos números podrían ser de interés por su integración temática. El número 42 lo integran siete artículos redactados en francés, porque se les dedicó a estudios sobre la lengua y la cultura francesas. Otros, como el número 35 , se dedican enteramente a la literatura costarricense; contiene dieciséis artículos sobre su narrativa: o el 38, que reúnen artículos en torno a la literatura fantástica, analizada desde distintas perspectivas culturales. En 1994, se publica un número doble —el 29-30 — que recoge las charlas y conferencias con ocasión del vigésimo aniversario de la Escuela de Literatura y Ciencias del Lenguaje. Versan sobre la narrativa latinoamericana, la adquisición una segunda lengua y sobre la lengua bribri. Otro caso particular es el número 22 -único de su índole, por tratarse de un 
número enteramente monográfico, y sobre una escritora-, en el que se publica una extensa bibliografía comentada de la escritora costarricense Carmen Naranjo: contiene una breve biografía y dilatada información de su obra literaria y de la crítica alrededor de ella.

Letras ha adoptado a lo largo de los años una vocación integradora y dialogante, desde el punto de vista académico, disciplinario y epistemológico. Eso, dentro de ciertas limitaciones materiales y financieras de la institución, no deja de ser un mérito notable. En otras circunstancias, pudo haber sido de desear contar con sendas revistas dedicadas enteramente a los estudios lingüísticos, a los estudios de crítica y teoría literarias, incluso con una revista estrictamente dedicada a la creación literaria. Con Letras, lejos de excluir, se ha buscado integrar y propiciar la coexistencia de estos variados campos del saber y del quehacer intelectual y artístico. De ese modo, se da opción a dar con puntos o aspectos en común, aun entre especialidades tan variadas y, en apariencia, diversas. Hoy día convergen no pocas áreas de conocimiento, disciplinas y espacios del saber: lingüística general, lingüística aplicada, estudios traductológicos, monografías sobre literatura, relaciones entre cine y literatura, corrientes de la fonología contemporánea, acercamientos a las lenguas indígenas costarricenses, estudios sobre el canon artístico y literario, adquisición o enseñanza de lenguas, estudios sobre variantes del español; incluso, los denominados hoy día estudios culturales, en su amplia gama de orientaciones y temas.

\section{Una puerta al espacio internacional}

De esa historia, además, conviene mencionar algunas observaciones sobre su desarrollo material. Vista en su conjunto, se observan dos etapas: la primera, de los números 1 a 10, fue una publicación con tomos de más de 200 páginas, que combinó aspectos de una revista artística y literaria (poesía, cuento, pintura) con los de una propiamente académica. La segunda, desde el número 11 hasta la actualidad, corresponde a su consolidación institucional; sus entregas 
se concentran en estudios literarios y lingüísticos, la enseñanza de lenguas, la traducción y la traductología, y las lenguas indígenas. Esta segunda etapa también ha llevado a novedades, con el tirón de las nuevas tecnologías y opciones de la comunicación; así, la revista se sigue difundiendo en su versión impresa convencional y a partir del segundo semestre de 2011 en una versión digital. Con ello, Letras se acopla a los ritmos de la comunicación contemporánea, y fortalece sus características como revista académica con estándares internacionales: un acceso rápido y eficaz a sus contenidos, intercomunicación con sus pares (nacionales e internacionales), y un contacto efectivo y dinámico con la comunidad académica.

La considerable transformación de la actividad editorial ha hecho imperativa la innovación. Durante la etapa de transición tecnológica, también ha sido insoslayable afrontar las nuevas condiciones y exigencias en los procesos de edición. Estar al día en esa materia es parte de las tareas de la revista, de sus administradores y de las políticas generales de la institución.

\section{Epílogo}

Como ha quedado dicho, Letras es una de las primeras revistas académicas fundadas por la Universidad Nacional, y sigue tan activa como durante su etapa inaugural. Ha cumplido su misión de abrir nuevos espacios al conocimiento y al desarrollo de las áreas del conocimiento que impulsa, y a la vez fecunda, la actividad académica de la cuna donde nació, la Escuela de Literatura y Ciencias del Lenguaje. Estos cincuenta números, publicados durante más de tres decenios son el testimonio material e intelectual de una historia que empezó con un tomo - aquel primero fue de 218 páginas, en formato de cuarto de folio, con tapa en verde olivo- y que hoy se ha convertido en un espacio internacional, ya inserto en una red de comunicación planetaria, como lo exigen las circunstancias y las nuevas condiciones de la cultura. 